\title{
Protocol for collaboration between the National Genebank and Community Seed Banks
}

Version June 2021

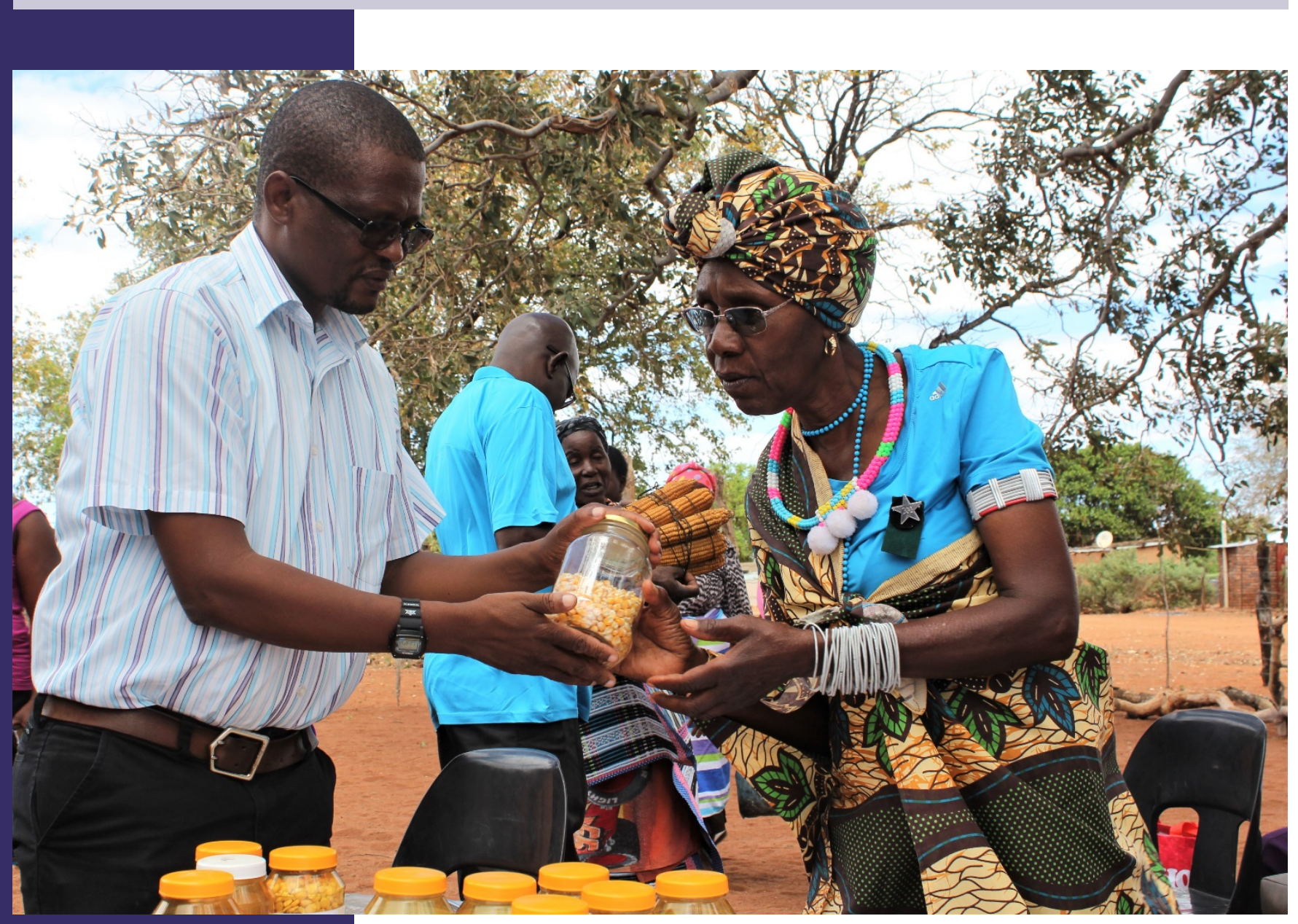

\section{Developed by}

Community Technology

Development Trust (CTDT), Zimbabwe

Seed Savers Network-Kenya (SSN)

National Agricultural Research

Organisation - Plant Genetic Resources

Centre (NARO-PGRC), Uganda

Wageningen Centre for Development Innovation, Wageningen University and Research (WCDI-WUR), The Netherlands

The Alliance of Bioversity International and CIAT, Italy

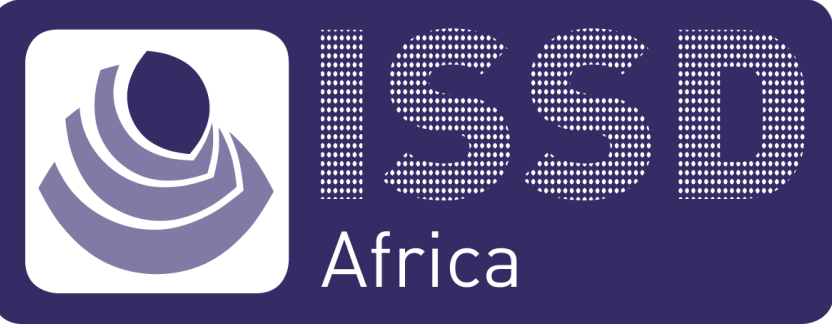




\section{Front cover photo:}

The curator of South Africa's national Plant Genetic Resources Centre and a member of the Gumbu community seed bank inspect maize seed to be stored in the community seed bank.

Credit: The Alliance of Bioversity International and CIAT/R.Vernooy 


\section{ISSD Africa Community of Practice}

\section{Protocol for collaboration between the National Genebank and Community Seed Banks}

Developed by:

1. Community Technology Development Trust (CTDT), Zimbabwe

2. Seed Savers Network (SSN), Kenya

3. National Agricultural Research Organisation - Plant Genetic Resources Centre (NARO-PGRC), Uganda

4. The Alliance of Bioversity International and CIAT, Italy

5. Wageningen Centre for Development Innovation, Wageningen University and Research (WCDI-WUR), The Netherlands
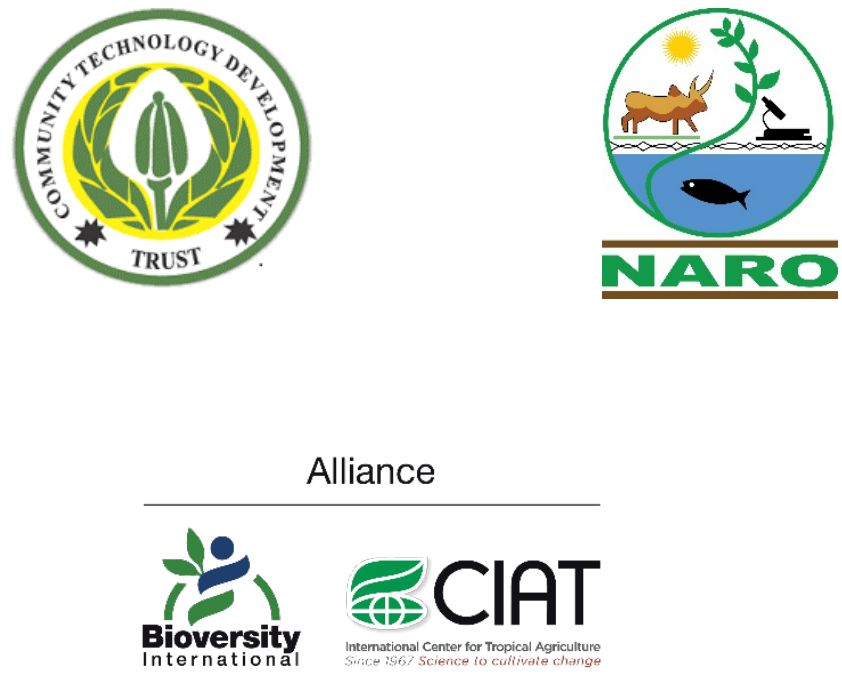

WAGENINGEN

UNIVERSITY \&. RESEARCH

Version 1, June 2021

ISSD Africa No. 2021-02

This report can be downloaded for free at https://doi.org/10.18174/548326

(cc) BY-NC Creative Commons Attribution 4.0 (Netherlands) license. To view a copy of this license, visit

https://creativecommons.org/licenses/by-nc/4.0/ 


\section{Background}

In recent years, national genebanks of some countries (e.g. Bhutan, Mexico, Nepal, South Africa and Uganda) have started to collaborate with community seed banks on the important task of conservation of crop (and tree) varieties. This collaboration has taken place in informal ways, in the form of participation in meetings and gatherings, seed and food fairs and through a number of joint activities, including the establishment of community seed banks and related (capacity development) activities. As far as is known, no formal agreements have been made/signed to structure, monitor and evaluate the collaboration in a more rigorous manner.

Based on interactions among professionals from various countries who support community seed banks, it was decided to develop a generic collaboration protocol that could help shape the collaboration process in countries where this has not yet taken place or to solidify the process in countries where this is already happening.

The protocol document includes chapters (articles) on the roles of the national genebank; the roles of community seed banks; principles of collaboration; activities that can be done together and rules and regulations for the collaboration. It benefitted from the inputs of many partners in Kenya, South Africa, Uganda and Zimbabwe and from the long community seed bank working experience of staff of Bioversity International, now the Alliance of Bioversity International and CIAT.

\section{The Protocol}

\section{Preamble}

Realizing the importance of the national genebank in relation to the conservation and sustainable use of plant genetic resources for the benefit of the present and future generations;

Affirming the important roles that farmers and farming communities play in community-based management of plant genetic resources;

Realizing the need for greater cooperation between the national genebank and the community seed banks in the conservation and sustainable utilization of the genetic resources, the adaptation to climate change and the provision of healthy and nutritious foods;

Realizing the importance of promoting equity and fairness in discussions and negotiations of mutually agreed terms for the collaboration between the national genebank and the community seed banks;

The national genebank and the community seed banks have agreed on the following: 


\section{Article 1}

\section{Functions of the National Genebank}

The national genebank is the national institution for the coordination and implementation of all activities concerned with crop genetic resources for the benefit of present and future generations. It also supports farmers in community-based management of crop genetic resources, which includes adaptation to climate change and the provision of healthy and nutritious foods. The core activities of the national genebank include seed collection, processing, conservation, multiplication, regeneration, characterization, evaluation and documentation of priority species, with special attention paid to farmerpreferred seed for local use.

\section{Functions of the Community Seed Bank}

The community seed bank shall ensure and enhance seed conservation of local/farmer (indigenous and heirloom) plant genetic resources, restoring them when needed, and supplying them to local farmers at low cost and without bottlenecks through continuous (seasonal and annual) multiplication. It shall also enhance crop and varietal diversity to provide healthy and nutritious food and to address new demands of farmers in the context of changing (climatic) conditions. The community seed bank will complement its conservation and exchange functions through value-addition activities that can support its operations in the long run.

\section{Article 2}

\section{Objectives}

The objective of this Protocol is to foster coordination and collaboration between the national genebank and community seed banks (CSBs) on conservation, sustainable use and seed production and exchange, contributing to stronger national seed systems and healthier food systems, and the achievement of seed and food sovereignty of communities and the nation.

\section{Specific objectives are:}

i) Strengthen the capacities of CSBs as centers for the conservation and sustainable use of local germplasm, which includes activities such as collection and characterization of crop varieties, dissemination of local knowledge related to crops, promotion of ecological farming practices, and crop/variety experimentation to assess the suitability, adaptability, health and nutritional values and economic viability of accessions held by the CSBs.

ii) Support and strengthen farmers' capacity to collect germplasm locally, create a local database, carry out GIS mapping, exchange seed between and among CSBs, and cooperate with scientists, policy-makers, local authorities, universities and public sector research institutions.

iii) Facilitate institutional linkages with formal crop conservation and improvement programs at national, regional and global levels for the purpose of accessing promising varieties and advanced and segregating materials (and related information) to enhance the climate adaptation efforts of CSBs and farming communities.

iv) Embark on participatory plant breeding (PPB), participatory variety selection (PVE) and participatory crop enhancement (PVE) activities, which will strengthen the social capital of CSBs and farming communities to produce biodiverse, nutritious food;

v) Create favorable conditions to respect and protect farmers' varieties and related knowledge and avoid misappropriation and abuse of these varieties and that knowledge.

vi) Raise awareness and advocate for the formulation and implementation of enabling policies and laws that recognize and support the expertise and efforts of CSBs and farmer seed systems at large. 


\section{Article 3}

\section{Scope}

This Protocol shall promote the establishment of community seed banks at local level; promote regional, national and international cooperation; promote knowledge management and exchange of plant genetic resources for food agriculture, onfarm seed production and marketing, and data management. This Protocol shall apply to plant genetic resources (seed) maintained by the national genebank and the community seed banks; to the traditional knowledge associated with plant genetic resources; and to the benefits arising from the utilization of such knowledge.

\section{Article 4}

\section{Resilient and Integrated Seed Systems}

This Protocol shall promote the establishment of resilient and integrated seed systems in the country supported by appropriate policies and legislation.

\section{Article 5}

\section{Guiding Principles of the Collaboration}

This Protocol between the national genebank and the community seed banks shall be guided by the following principles:

- collaboration will be based on honesty, integrity, reliability and commitment to achieve common goals

- collaboration will be based on mutual respect for each other's knowledge and skills

- collaboration includes the engagement with other stakeholders to achieve common goals

- $\quad$ CSB members will be involved in decision making

- collaboration will be sustained through regular communication and effective teamwork

- collaboration will be guided by simple procedures, rules and regulations

- the roles of women as important seed custodians and managers will be recognized and supported.

\section{Article 6}

\section{Rules Governing the Collaboration under this Protocol}

For effective collaboration between the national genebank and the community seed banks, the following shall be taken into consideration:

- $\quad$ seed in the CSBs belongs to the farmer members and their communities and they have the right to decide about its uses(s)

- the national genebank and the CSBs will strive to carry out regular reciprocal seed donations and/or exchanges, based on the principle of Prior Informed Consent

- $\quad$ seed donated to each other by and/or exchanged between the national genebank and CSBs will be free of charge

- the national genebank will provide technical support to the CSBs to strengthen their operations

- $\quad$ whenever appropriate, mention will be made of the contributions of the collaborators to joint activities

- whenever required, the knowledge and skills of seed experts will be mobilized to advance the collaboration. 


\section{Article 7}

\section{Possible Collaborative Activities}

The national genebank and the community seed banks strive to work together to:

- $\quad$ ensure that communities have seed in their hand that is adapted to the area, through targeted multiplication

- $\quad$ properly document local/farmer varieties (database development and maintenance)

- $\quad$ identify lost varieties of high value and conserve the most threatened or endangered species/varieties

- $\quad$ reintroduce lost varieties of high value in the community, where the national genebank can provide the lost varieties and the CSBs help in multiplication and storage at the community seed bank

- carry out research on and incorporate new research findings concerning new technologies for the storage, conservation and multiplication of plant genetic materials

- document and share information regarding new findings and emerging dynamics

- $\quad$ promote agroecology and crop diversification as sound agricultural management practices

- $\quad$ organize seed (diversity) fairs and exchange visits

- $\quad$ work together on participatory crop improvement

- train farmers on conservation methods

- $\quad$ build capacity for the production of quality seed for the benefit of the farming communities

- $\quad$ promote the CSB as a platform for community development.

\section{Article 8}

\section{Relationship with National Policies and Legislation}

This Protocol shall be implemented in respect of and in a mutually supportive manner with national policies and legislation relevant to the Protocol:

- $\quad$ promote crop diversification

- $\quad$ promote the CSB as a platform for community empowerment

- $\quad$ promote the CSB as one of the effective means for the implementation of national actions on climate change adaptation.

\section{Article 9}

\section{Compliance with this Protocol}

The national genebank and the community seed banks shall take appropriate and effective measures to ensure that the plant genetic resources utilized have been accessed in accordance with the principle of Prior Informed Consent and respecting the mutually agreed terms of this Protocol. 


\section{Article 10}

\section{Assessment and Review}

The national genebank and the community seed banks shall regularly review, carefully monitor and evaluate the effectiveness of this Protocol as and when required.

\section{Article 11}

\section{Effective date}

This Protocol shall come into operation on [date].

\section{Signatures}

On behalf of the national genebank: [signature]

On behalf of the community seed bank: [signature] 


\section{Acknowledgements}

This Protocol was developed based on the inputs from staff of lead plant genetic resources conservation and agricultural research and development organizations in East and Southern Africa, the Wageningen Centre for Development Innovation of Wageningen University and Research in the Netherlands (WCDI-WUR) and the Alliance of Bioversity International and CIAT (the Alliance). Lead contributors are Dominic Kimani of the Seed Savers Network in Kenya, Joyce Adokorach of the National Agricultural Research Organisation (NARO) in Uganda, Andrew Mushita of the Community Technology Development Trust in Zimbabwe, Abishkar Subedi of WCDI-WUR and Ronnie Vernooy of the Alliance.

We acknowledge the financial support of the Ministry of Agriculture, Food Quality and Nature of the Kingdom of the Netherlands under the collaborative agreement 'Resilient Seed Systems for Climate Change Adaptation and Livelihood Security'. In addition, we acknowledge the financial support provided by the Integrated Seed Sector Development in Africa (ISSD Africa) 2019-2022 project and by the CGIAR Research Program on Climate Change, Agriculture and Food Security (CCAFS). CCAFS is carried out with support from the CGIAR Trust Fund and through bilateral funding agreements. For details, please visit https://ccafs.cgiar.org/donors. The views expressed in this document cannot be taken to reflect the official opinions of these organizations.

We thank Cinzia Russo for editing.

\section{Citation:}

Community Technology Development Trust (CTDT); Seed Savers Network-Kenya (SSN); National Agricultural Research Organisation - Plant Genetic Resources Centre (NARO-PGRC); Wageningen Centre for Development Innovation, Wageningen University and Research (WCDI-WUR) and the Alliance of Bioversity International and CIAT. (2021) Protocol for Collaboration between the National Genebank and Community Seed Banks. Wageningen (The Netherlands): ISSD Africa and Rome (Italy): The Alliance of Bioversity International and CIAT. 
Protocol for collaboration between the National Genebank and Community Seed Banks

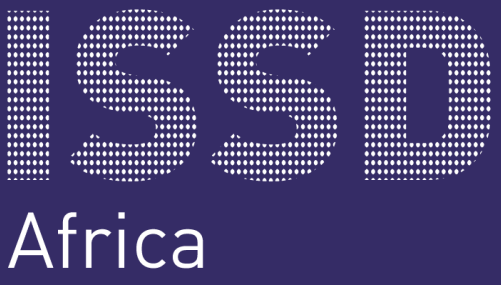

